\title{
Pankreatitis akutua duen pazientearen artatzea
}

\author{
Management of patients with acute pancreatitis \\ Felix Zubia-Olaskoaga \\ Zainketa Intentsiboen Unitatea. Donostialdea ESI \\ Medikuntza Saila. Donostia Unibertsitate Ospitalea. Euskal Herriko Unibetsitatea, UPV/EHU \\ felix.zubiaolascoaga@osakidetza.eus
}

\section{Laburpena}

Pankreatitis akutua pankrearen gaixotasun onbera eta akutua da. Kasurik gehienetan arina izan ohi da, baina formarik larrienetan hilkortasun- eta konplikazio-tasa handiak izan ditzake. Kasu larri horietarako, oso garrantzitsua da espezialitate anitzeko protokolo bat izatea, maila ezberdinetan eman beharreko arreta hitzartua duena. Berrikuspen-lan honetan maila ezberdin bakoitzean eman beharreko arreta egokia deskribatzen da. Larrialdi Zerbitzuetan: Diagnostikoa egin, Analgesia egokia, Larritasun-mailaren balorazioa, Hidratazio egokia hasi. Ospitaleratze Unitateetan: Ezinbestekoa da pazientearen larritasuna modu kliniko eta analitikoan egiaztatzea, 12 orduan behin, lehen 48 orduetan. Edozein momentutan organo-gutxiegitasun datuak atzematen badira, pazientea Zainketa Intentsiboen Unitatean artatu behar da. Horretaz gain, honako neurri hauek hartuko dira: analgesia mantendu, hidratazio egokia eman, elikadura hasi, sabelalde barneko presioa neurtu, erradiologiaprobak egin. Antibiotiko enpirikoaren erabilera ez da gomendatzen. Kirurgiarako indikazioak: Tratamendu medikoarekin konpontzen ez den sabelalde barneko presioaren igoera larria, nekrosi infektatua (neurri minimoki inbaditzaileez saia liteke lehen urrats moduan, edo step-up estrategia), hesteen zulaketa, hemorragia akutua (erradiologia interbentzionista erabiltzen da normalean). Ondorioak: Pankreatitis akutua gaixotasun arina da gehienetan, baina kasurik larrienetan hilkortasuneta konplikazio-tasa altua ditu. Horiek artatzeko protokolo bat izatea eta parte hartzen duten espezialista ezberdinen elkarlana ezinbestekoa da.

Gako-hitzak: pankreatitis akutua, protokolo klinikoa, kirurgia.

\section{Abstract}

Acute pancreatitis is an acute but benign disease of the pancreas. It is usually a mild illness, but in its most severe forms mortality and morbidity can be high. For these severe forms of the disease, it is very important to have a multidisciplinary protocol for clinical management at the different levels of assistance. In this review, we describe the optimal measures for each level of assistance. Emergency Department: diagnose correctly, adequate analgesia, severity assessment, initiate correct volume replacement. Hospitalization units: clinical and analytical assessment of severity every 12 hours is essential during the first $48 \mathrm{~h}$. If signs of organ failure are present, the patient should be admitted to the Intensive Care unit. The following procedures should be taken: maintain analgesia, appropriate hydration, commence nutrition, measure intra-abdominal pressure and perform radiological tests. The use of antibiotic prophylaxis is not recommended. Indications for surgery: an increase in intraabdominal pressure in the absence of response to medical treatment, infected necrosis (could be initially managed with minimally invasive measures, step-up approach), intestinal perforation and acute hemorrhage (usually managed by interventional radiology). Conclusions: acute pancreatitis is usually a mild disease, but in its most severe forms it can lead to high mortality and morbidity. The development of a multidisciplinary protocol and the collaboration and coordination of different specialists is imperative for the correct management of these patients.

Keywords: acute pancreatitis, clinical protocol, surgery.

Bidalia: 2017ko uztailaren 31n.

http://doi.org/10.26876/osagaiz.2.2017.94

Onartua: 2017ko azaroaren 16an. 


\section{Sarrera eta helburuak}

Pankreatitis akutua pankrearen hanturak eragindako gaixotasun onbera da. Haren eragile nagusiak behazun-bideetako kalkuluak eta alkohola dira (1), eta mundu-mailan haren intzidentzia gorantz doa, obesitateari loturik batik bat (2). Uneotan, ospitaleratzea eragiten duten digestio-aparatuko patologien artean nagusiena da $(3,4)$.

Pankreatitis akutuaren bilakaera klinikoak bi fase ditu (5). Lehen astean, Hanturazko Erantzun Sistemikoaren Sindromea garatu liteke, nekrosiak eragindako bitartekariak direla-eta. Behin egun horiek pasa eta gero, nekrosiak konplikazio lokalak eragin ditzake, nekrosi infektatua, hesteen zulaketa eta hemorragia akutua batez ere.

Pankreatitis akutua duten paziente gehienek (\% 85 inguru) eboluzio arina izaten dute, eta egun gutxitan osatzen dira. Baina kasuen \% 15-20 okertu egiten dira, morbilitate- eta hilkortasun-tasa handiarekin (\% 20tik gorakoa, Zainketa Intentsiboen Unitatera iristen bada)(6-9). Berrikuspen honetan, pankreatitis akutua duen pazientearen arretak nolakoa beharko lukeen deskribatuko dugu, formarik larrienetan batez ere. Garrantzitsua da ospitale edo ESI bakoitzak bere protokolo egokitua izatea, Larrialdi, Erradiologia, Laborategi, Kirurgia Orokor, Digestio Aparatu eta Zainketa Intentsiboen Unitateetako espezialistek osaturiko lantalde batekin, nazioarteko gidek gomendatzen duten moduan (10). 1. irudian paziente hauen arreta jasoko lukeen diagrama deskribatzen da, haien ospitaleratze osoan zehar.

\section{Pankreatitis akutuaren diagnostikoa}

Pankreatitis akutua diagnostikatzeko, honako irizpide hauetatik bi izan behar ditu pazienteak (11): sabeleko mina, amilasa- edo/eta lipasa-mailak oinarrizkoen gainetik hiru aldiz igotzea, eta irudiprobetan bateragarria den emaitza izatea.

\section{Pankreatitis akutua duen paziente baten arreta Larrialdi ZerbitzuanSarrera eta helburuak}

Behin diagnostikoa eginda, Larrialdi Zerbitzuan honako pauso hauek eman beharko genituzke.

- Analgesia egokia, antiinflamatorio ez-esteroideoak erabiliz, eta beharrezkoa balitz, opiazeoak erabiliz. Aurrez uste zenaren aurka, morfina erabiltzeko inolako eragozpenik ez dago paziente hauetan (12).

- Organo-gutxiegitasunaren balorazio egokia egin (13). Lehen egunetan Hanturazko Sindrome larria ager liteke, batez ere shocka, arnas gutxiegitasuna eta giltzurrun-gutxiegitasuna. Miaketa fisikoan eta odol-analisian hemograma, giltzurrun-funtzioa eta ioiak eta koagulazioa aztertu beharko genituzke, eta arnas gutxiegitasunaren zeinurik balego, arteriako gasometria bat ere bai.

- Pazientearen hidratazioa hasi (14). Pankreatitis akutuan hipobolemia egoera eman ohi da sarritan, pazienteak edateko arazoak dituelako, eta sabelaldeko hirugarren espazioak bolumen-galera eragin dezakeelako. Shock egoeran badago, hidratazio indartsua hasi beharko dugu, serum isotonikoa emanez, hainbat adituk dioenez orduko $300 \mathrm{~mL}$-ko erritmoan. Shock egoerarik ez badago, hidratazio arinagoa egin behar da.

- Erradiologia. Sabelaldeko ekografiak ez du pankrea aztertzeko aukera egokirik ematen gehienetan, hesteetako aireak galarazten duelako (15). Haren balio nagusia etiologia zehaztea da, behazun-bidean kalkulurik baden ala ez adierazten digulako. Sabelaldeko OTAk pankrearen itxura ikusten laguntzen $\mathrm{du}$, eta Balthazar-en eskala erabiliz, larritasunaren aurreikuspena egin liteke (16). Pankrearen nekrosia ikusteko baina, 48 orduko eboluzioa behar izaten da, eta hori dela-eta, organo-gutxiegitasunik ezean atzeratzeko gomendatzen da (17).

Behin neurri horiek hartuta, pazientearen larritasunaren balorazioa egingo dugu. Organogutxiegitasunen bat bada, Zainketa Intentsiboen Unitatera joan beharko du pazienteak, eusteneurriak indartzeko (18). Kontuan hartu behar dugu pankrearen eta inguruko ehunen hantura 
murrizten duen tratamendurik ez dagoela, eta, beraz, euste-neurrietan eta denboran oinarritzen dela tratamendua.

Organo-gutxiegitasunik ez bada, ospitaleratu egingo dugu pazientea, ahal dela hartzen duen zerbitzuaren mediku arduradunari honen berri emanez.

\section{Pankreatitis akutua duen pazientearen arreta Ospitaleratze Unitatean}

Behin ospitaleratzea eginda, oso garrantzitsua da pazientearen ebaluazio jarraitua egitea, 12 orduan behin gutxienez, lehen lau egunetan (19). Hainbat larritasun-zeinu kliniko, analitiko eta erradiologiko deskribatu dira (ikus 1. irudia), baina oso balio prediktibo positibo baxua dute. Zaila denez aurreikustea zein pazientek garatuko duen Hanturazko Erantzunaren Sindrome Sistemikoa, bai analitikoki eta bai bestelako metodoak erabiliz, jarraipen klinikoa eta analitikoa oso garrantzitsuak dira, organo-gutxiegitasunen bat garatzen badu, horiei aurre egiteko (20).

Oro har, pazientea artatzeko hauek dira neurri nagusiak:

- Analgesia egokia lortzea.

- Lehen bi egunetan baraurik egongo denez, hidratazio egokia mantendu behar dugu. Lehen egunean hidratazioak indartsuagoa izan behar du, eta betiere diuresia ondo neurtuz, aurrez azaldu den moduan paziente hauek hipobolemia garatzeko arrisku handia dutelako (21).

- Organo-gutxiegitasunik garatzen ez badu, pixkanakako dietari ekingo zaio, koipeak saihestuz. Elikadura egokirik lortzen ez bada, elikadura enterala erabili beharko dugu, zunda nasogastrikoa edo nasojeiunala erabiliz (22). Elikadura enteralak bakterioen translokazioa galarazten du, eta haren erabilerak nekrosiaren infekzioa eta hilkortasuna murrizten ditu. Duela urte batzuk aipatzen zen «pankrearen atsedena» zaharkitua geratu da, eta neurri desegokia da.

- Paziente hauek ez dute inolako antibiotikorik behar, pankreako nekrosia infektatu ez dadin (23). Orain dela urte batzuk gomendatzen bazen ere, diseinu egokia zuten saiakuntza klinikoak garatzean erabileraren desegokitasuna frogatu zen, infekzioen eta hilkortasunaren tasa ez dutela hobetzen ikusi baitzen (24).

- Sabelalde barruko presioaren neurketa. Maskuri barruko presioa neurtuz egiten da, uretrako zunda bat erabiliz. Pankreatitisa larria bada, sabelaldeko presioa igo egingo da, kasurik larrienetan arnas gutxiegitasuna eta giltzurrun-gutxiegitasuna eraginez (25). Haren neurketa kasu guztietan gomendagarria bada ere, organo-gutxiegitasunen bat garatzen ari den pazientean ezinbestekoa da (26).

- Erradiologia. Aurrez aipatu den moduan, pankrearen nekrosia OTAn ongi ikusteko 48 ordu behar dira gutxienez. Pazientearen bilakaera ona bada, eta inolako konplikaziorik gabea, ekografia bat egitea nahikoa litzateke, etiologia ezagutzeko batez ere. Konplikazioren bat bada, OTA egin beharko genuke, pankrea eta inguruko egiturak hobeto ikusteko, behin 48 ordu pasa ondoren bereziki.

- Atzeranzko kolangiopankreatografia endoskopikoa geroz eta gutxiago erabiltzen den baliabidea da. Haren indikazioak pankreatitis biliarrean bakarrik gertatzen dira, kalkulu batek koledokoaren estasia edo/eta kolangitisa eragiten baditu (27).

- Pankreatitisa behazuneko kalkuluek eragindakoa denean, pazienteari kolezistektomia bat egin beharko zaio, behin hantura pasa eta gero, pankreatitisaren agerraldi berririk gerta ez dadin (28).

- Tronbosi benoso sakonaren profilaxia egin behar da, pazientea oheratua dagoen bitartean.

Arestian aipatu den moduan, paziente hauen balorazio jarraitua egin beharra dago, hamabi orduan behin lehen lau egunetan, eta edozein momentutan organo-gutxiegitasunen bat garatzen hasten bada, Zainketa Intentsiboen Unitatearekin harremanetan jarri beharko dugu euste-neurriak indartzeko.

\section{Kirurgiarako indikazioak}

Pankreatitis akutua gaixotasun lokal eta kirurgikoa izatetik, gaixotasun mediko eta sistemikoa izatera pasa da azken urteotan. Kirurgiaren indikazioak, ondoren datozenak, konplikazioei lotuak dira (29). 
- Tratamendu medikoaz (xurgatuz doan zunda nasogastrikoa, analgesia, prozinetikoak) konpontzen ez den sabelaldeko presioaren igoera, sabelaldeko konpartimentuko sindromea saihesteko laparotomia bat eginez.

- Nekrosi infektatua. Azken urteotan hain inbaditzaileak ez diren tekniken erabilera gomendatzen da lehen neurri bezala (erradiologia edo endoskopia bidez drainatzea), eta horiek nahikoa ez badira, kirurgia zabalera jotzea (step-up prozedura) (30).

- Hesteen zulaketa, nekrosi pankreatikoak eragina. Ostomia bidez konpontzen da gehienetan.

- Hemorragia akutua, nekrosiak eragindako pseudoaneurismen ondorioz. Erradiologia interbentzionista bidez konpontzen dira (31).

\section{Pankreatitis akutua duen pazientearen sailkapena}

Pankreatitis akutua sailkatzeko, urte askoan Atlantako sailkapena erabili izan da, 1992an sortua (32). Sailkapen horrek baina, larritasun gutxiko pazienteak ere larrien taldean sartzen ditu, eta horregatik baztertua izan da. Badakigu pankreatitis akutu baten garapena baldintzatzen duten bi faktore nagusiak organo-gutxiegitasunaren garapena eta pankrearen nekrosiaren infekzioa direla $(33,34)$. Horretan oinarriturik, bi sailkapen berri garatu dira azken urteotan, ezberdintasun txiki batzuk dituztenak elkarren artean: Atlantako Sailkapen Berrikusia, eta Determinanteetan Oinarrituriko Sailkapena $(35,36)$. Sailkapen-sistema hauek baina, pazientearen bilakaeraren bukaeran soilik erabil daitezke, lehen momentuan ez dakigulako organo-gutxiegitasuna garatuko duten ala ez, eta nekrosia infektatuko den ala ez. 1. taulan bi sailkapenok deskribatzen ditugu. Dena den, gure ikerketa-taldeak ikusi du Determinanteetan Oinarrituriko Sailkapenak hainbat arazo dituela, talde berean bilakaera ezberdineko pazienteak sartzen dituelako: organo-gutxiegitasun mantendua duten pazienteak, baina nekrosi infektaturik garatzen ez dutenak batetik; eta organo-gutxiegitasun mantendurik ez dutenak, baina nekrosiaren infekzioa garatzen dutenak bestetik. Hori dela eta, sailkapen-sistema berri bat proposatu dugu, eta ikuskizun dago nola garatuko den (37).

\section{Ondorioak}

Pankreatitis akutua gaixotasun arina da gehienetan, baina kasurik larrienetan hilkortasun- eta konplikazio-tasa altuak ditu. Horiek artatzeko ezinbestekoa da protokolo bat izatea eta parte hartzen duten espezialista ezberdinen elkarlana lortzea.

1. taula. Atlantako Sailkapen Berrikusiaren, Determinanteetan Oinarrituriko Sailkapenaren eta Determinanteetan Oinarrituriko Sailkapen Aldatuaren arteko konparaketa, pazientearen egoera klinikoan oinarritua.

\begin{tabular}{|c|c|c|c|}
\hline Egoera klinikoa & $\begin{array}{c}\text { Atlantako } \\
\text { Sailkapen } \\
\text { Berrikusia }\end{array}$ & $\begin{array}{c}\text { Determinanteetan } \\
\text { Oinarrituriko } \\
\text { Sailkapena }\end{array}$ & $\begin{array}{c}\text { Determinateetan } \\
\text { Oinarrituriko } \\
\text { Sailkapen Aldatua }\end{array}$ \\
\hline $\begin{array}{c}\text { Organo-gutxiegitasunik ez } \\
\text { Nekrosi infektaturik ez }\end{array}$ & Arina & Arina & 0 \\
\hline $\begin{array}{c}\text { Organo-gutxiegitasun } \\
\text { iragankorra } \\
\text { Nekrosi infektaturik ez }\end{array}$ & Ertaina & Ertaina & 1 \\
\hline $\begin{array}{c}\text { Organo-gutxiegitasun } \\
\text { iragankorra } \\
\text { Nekrosi infektatua }\end{array}$ & Ertaina & Larria & 2 \\
\hline $\begin{array}{c}\text { Organo-gutxiegitasun } \\
\text { mantendua } \\
\text { Nekrosi infektaturik ez }\end{array}$ & Larria & Larria & 3 \\
\hline $\begin{array}{c}\text { Organo-gutxiegitasun } \\
\text { mantendua }\end{array}$ & Larria & Kritikoa & 4 \\
\hline Nekrosi infektatua & &
\end{tabular}




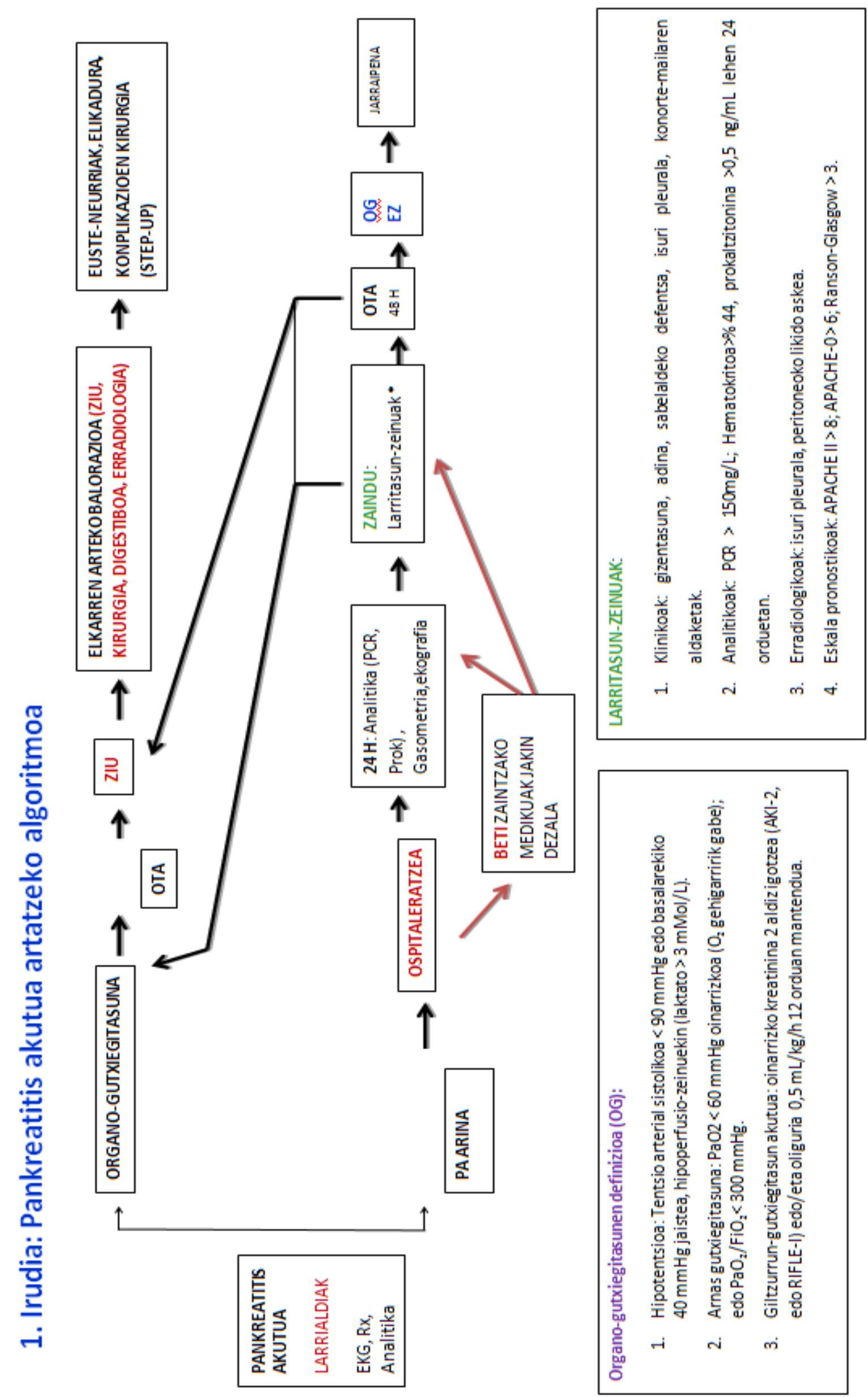




\section{Erreferentzia bibliografikoak}

1. Bai Y, Liu Y, Jia L, Jiang H, Ji M, Lv N, Huang K, Zou X, Li Y, Tang C, Guo X, Peng X, Fang D, Wang B, Yang B, Wang L, Li Z. Severe acute pancreatitis in China: etiology and mortality in 1976 patients. Pancreas. 2007;35(3):232-7

2. Bolado F, de-Madaria E. Novedades en el manejo de la pancreatitis aguda. Gastroenterol Hepatol. 2016;39 Suppl 1:102-108.

3. Campos T, Parreira JG, Utiyama E, Rasslan S. Pesquisa nacional sobre condutas na pancreatite aguda. Rev. Col. Bras. Cir. 2008;35(5): 304-310.

4. Fosmark CE, Vege SS, Wilcox M.Acute pancreatitis. N Engl J med 2016375: 1972-1981.

5. Lankisch P. Natural course of acute pancreatitis: what we know today and what we ought to know for tomorrow. Pancreas. 2009;38:494-8.

6. Bumbasirevic V, Radenkovic D, Jankovic Z, Karamarkovic A, Jovanovic B, Milic N, Palibrk I, Ivancevic $N$. Severe acute pancreatitis: overall and early versus late mortality in intensive care units. Pancreas. 2009;38(2):122-5.

7. Gloor B, Müller CA, Worni M, Martignoni ME, Uhl W, Büchler MW. Late mortality in patients with severe acute pancreatitis. Br J Surg. 2001;88(7):975-9

8. Carnovale A, Rabitti PG, Manes G, Esposito P, Pacelli L, Uomo G. Mortality in acute pancreatitis: is it an early or a late event? JOP. 2005;6(5):438-44

9. Fu CY, Yeh CN, Hsu JT, Jan YY, Hwang TL. Timing of mortality in severe acute pancreatitis: experience from 643 patients. World J Gastroenterol. 2007;13(13):1966-9

10. McCallum IJ, Hicks GJ, Attwood S, Seymour K. Impact of a care pathway in acute pancreatitis. Postgrad Med J. 2011;87:379-381.

11. Banks PA, Freeman ML, Practice Parameters Committee of the American College of Gastroenterology. Practice guidelines in acute pancreatitis. Am J Gastroenterol 2006;101:2379400.

12. Peiró AM, Martínez J, Martínez E, de Madaria E, Llorens P, Horga JF, Pérez-Mateo M. Efficacy and tolerance of metamizole versus morphine for acute pancreatitis pain. Pancreatology. 2008;8(1):25-9

13. Johnson $C D$, Abu-Hilal M: Persistent organ failure during the first week as a marker of fatal outcome in acute pancreatitis. Gut. 2004;53(9):1340-4.

14. Gardner TB, Vege SS, Chari ST, Petersen BT, Topazian MD, Clain JE, Pearson RK, Levy MJ, Sarr MG. Faster rate of initial fluid resuscitation in severe acute pancreatitis diminishes in-hospital mortality. Pancreatology. 2009;9(6):770-6

15. Bharwani N, Patel S, Prabhudesai S, Fotheringham T, Power N. Acute pancreatitis: the role of imaging in diagnosis and management. Clin Radiol. 2011;66:164-75.

16. Balthazar EJ. Acute Pancreatitis: Assessment of Severity with Clinical and CT Evaluation. Radiology 2002; 223:603-613.

17. Bollen TL. Imaging of acute pancreatitis: update of the revised Atlanta classification. Radiol Clin North Am. 2012;50(3):429-45.

18. Maraví Poma E, Zubia Olascoaga F, Petrov MS, Navarro Soto S, Laplaza Santos C, Morales Alava F, Darnell Martin A, Gorraiz López B, Bolado Concejo F, Casi Villarroya M, Aizcorbe Garralda M, Albeniz Arbizu E, Sánchez-Izquierdo Riera JA, Tirapu León JP, Bordejé Laguna L, López Camps V, Marcos Neira P, Regidor Sanz E, Jiménez Mendioroz F; Grupo de Trabajo CC - Recomendaciones PAPG 2012,GTEI-SEMICYUC. SEMICYUC 2012. Recomendaciones para el manejo en Cuidados Intensivos de la pancreatitis aguda. Med Intensiva. 2013;37(3):163-79.

19. Maraví Poma E, Laplaza Santos C, Gorraiz López B, Albeniz Arbizu E, Zubia Olascoaga F, Petrov MS, Morales FA, Aizcorbe Garralda M, Casi Villaroya M, Sánchez-Izquierdo Riera JA, López Camps V, Regidor Sanz E, Loinaz Bordonabe M, do Pico JL; Grupo Hoja de Ruta de la PAG en Intensivos; Scientific Committee of the SEMICYUC; Working Group on Infectious Diseases (GTEI-SEMICYUC). Hoja de ruta de los cuidados clínicos para la pancreatitis aguda: recomendaciones para el manejo anticipado multidisciplinar (clinical pathways). Med Intensiva. 2012;36(5):351-7.

20. Mounzer R, Langmead CJ, Wu BU, Evans AC, Bishehsari F, Muddana V, Singh VK, Slivka A, Whitcomb DC, Yadav D, Banks PA, Papachristou GI. Comparison of existing clinical scoring 
systems to predict persistent organ failure in patients with acute pancreatitis. Gastroenterology. 2012;142(7):1476-82.

21. De-Madaria E, Martínez J, Pérez-Mateo M. The dynamic nature of fluid resuscitation in acute pancreatitis. Clin Gastroenterol Hepatol. 2012;10:95-96.

22. Petrov MS, van Santvoort HC, Besselink MG, van der Heijden GJ, Windsor JA, Gooszen HG. Enteral nutrition and the risk of mortality and infectious complications in patients with severe acute pancreatitis: a meta-analysis of randomized trials. Arch Surg. 2008;143(11):1111-7

23. Jiang K, Huang $W$, Yang XN, Xia Q. Present and future of prophylactic antibiotics for severe acute pancreatitis. World J Gastroenterol 2012; 18: 279-284.

24. Maraví-Poma E, Gener J, Alvarez-Lerma F, Olaechea P, Blanco A, Domínguez-Muñoz JE; Spanish Group for the Study of Septic Complications in Severe Acute Pancreatitis. Early antibiotic treatment (prophylaxis) of septic complications in severe acute necrotizing pancreatitis: a prospective, randomized, multicenter study comparing two regimens with imipenem-cilastatin. Intensive Care Med. 2003;29(11):1974-80.

25. Aitken EL, Gough V, Jones A, Macdonald A. Observational study of intra-abdominal pressure monitoring in acute pancreatitis. Surgery. 2014;155(5):910-8.

26. Ke L, Ni HB, Sun JK, Tong ZH, Li WQ, Li N, Li JS. Risk factors and outcome of intra-abdominal hypertension in patients with severe acute pancreatitis. World J Surg. 2012;36(1):171-8.

27. Uy MC, Daez ML, Sy PP, Banez VP, Espinosa WZ, Talingdan-Te MC. Early ERCP in acute gallstone pancreatitis without cholangitis: a meta-analysis. JOP. 2009;10:299-305

28. Nealon WH, Bawduniak J, Walser EM. Appropiate timing of cholecystectomy in patients who present with moderate to severe gallstone-associated acute pancreatitis with peripancreatic fluid collections. Ann Surg 2004, 239: 741-749.

29. Bradley EL, Dexter ND. Management of severe acute pancreatitis. A surgical odyssey. Ann Surg. 2010;251:6-17.

30. van Santvoort HC, Besselink MG, Bakker OJ, Hofker HS, Boermeester MA, Dejong CH, van Goor H, Schaapherder AF, van Eijck CH, Bollen TL, van Ramshorst B, Nieuwenhuijs VB, Timmer R, Laméris JS, Kruyt PM, Manusama ER, van der Harst E, van der Schelling GP, Karsten T, Hesselink EJ, van Laarhoven CJ, Rosman C, Bosscha K, de Wit RJ, Houdijk AP, van Leeuwen MS, Buskens E, Gooszen HG; Dutch Pancreatitis Study Group. A step-up approach or open necrosectomy for necrotizing pancreatitis. N Engl J Med. 2010;362(16):1491-502.

31. Bergert H, Hinterseher I, Kersting S, Leonhardt J, Bloomenthal A, Saeger HD. Management and outcome of hemorrhage due to arterial pseudoaneurysms in pancreatitis. Surgery. 2005;137(3):323-8.

32. Bradley 3rd EL. A clinically based classification system for acute pancreatitis. Ann Chir 1993; 47(6):537-541.

33. Johnson $C D$, Abu-Hilal M. Persistent organ failure during the first week as a marker of fatal outcome in acute pancreatitis. Gut. 2004;53:1340-1344.

34. Petrov MS, Shanbhag S, Chakraborty M, Phillips AR, Windsor JA. Organ failure and infection of pancreatic necrosis as determinants of mortality in patients with acute pancreatitis. Gastroenterology. 2010;139(3):813-20.

35. Banks PA, Bollen TL, Dervenis C, Gooszen HG, Johnson CD, Sarr MG, Tsiotos GG, Vege SS; Acute Pancreatitis Classification Working Group. Classification of acute pancreatitis--2012: revision of the Atlanta classification and definitions by international consensus. Gut. 2013;62(1):102-11.

36. Dellinger EP, Forsmark CE, Layer $P$, Lévy $P$, Maraví-Poma E, Petrov MS, Shimosegawa $T$, Siriwardena AK, Uomo G, Whitcomb DC, Windsor JA. Pancreatitis Across Nations Clinical Research and Education Alliance (PANCREA). Determinant-based classification of acute pancreatitis severity: an international multidisciplinary consultation. Ann Surg. 2012 Dec;256(6):875-80.

37. Zubia-Olaskoaga F, Maraví-Poma E, Urreta-Barallobre I, Ramírez-Puerta MR,Mourelo-Fariña M, Marcos-Neira MP. Epidemiology of Acute Pancreatitis in Intensive Care Medicine Study Group. Comparison Between Revised Atlanta Classification and Determinant-Based Classification for Acute Pancreatitis in Intensive Care Medicine. Why Do Not Use a Modified Determinant-Based Classification? Crit Care Med. 2016 May;44(5):910-7. 